\title{
OS CAMINHOS DA MEMÓRIA NO BATUQUE DO CARNAVAL CARIOCA
}

Vinícius Ferreira Natal

No mundo do carnaval, a memória assume papel relevante na constituição das relações entre instituições e indivíduos. Para investigar tais articulações, este artigo tem como objetivo observar a dinâmica da memória nas escolas de samba cariocas, culminando no caso do Departamento Cultural da Acadêmicos do Salgueiro. Utiliza-se a história oral como método de pesquisa e análise para melhor elucidar as questões mnemônicas nesse campo. [abstract on page 281]

CARNAVAL, ESCOLAS DE SAMBA, ACADÊMICOS DO SALGUEIRO, DEPARTAMENTOS CULTURAIS, MEMÓRIA. 


\section{INTRODUÇÃO}

Ao percorrer a trilha que é o universo das escolas de samba, depara-se constantemente com o passado: lembranças de desfiles, sambas que ficaram conhecidos por sua irreverência, julgamentos considerados absurdos, merecimento ou não de determinado título. Para tais ações de recordação, recorre-se ao instrumento daquela que, imperceptivelmente para a maioria, possui grande influência nas relações entre os indivíduos e na constituição do carnaval: a memória.

Pretende-se refletir acerca do papel exercido pela memória no universo das escolas de samba do Rio de Janeiro, observando como esse conceito se articula no contexto do carnaval e o papel que ele exerce na constituição das relações entre os sujeitos envolvidos nessa manifestação.

Na presente análise, vai-se da visão macro à micro: inicia-se com a memória no universo das escolas de samba, de modo amplo, culminando em estudo de caso do Departamento Cultural da Acadêmicos do Salgueiro, escolhida por sua importância, adquirida por ser um dos grupos de mais destaque no âmbito da memória e da cultura do samba.

Parte-se da preocupação com o tempo histórico, que não cessa. Ele é contínuo, ingrato, e a cada segundo uma parcela de passado é produzida. Se esse acúmulo de parcelas não é encarado como uma forma de constituição de memória, perdem-se fatos, objetos, história.

A abordagem da história oral nesse sentido se fez mais do que necessária: além de ser utilizada como metodologia de pesquisa para coletar depoimentos dos sujeitos envolvidos no carnaval e, consequentemente, no contexto de produção mnemônica, ela serve como base de constituição das próprias estratégias de preservação da memória por parte desses grupos.

Essa metodologia tem como característica resgatar as "memórias subterrâneas", que seriam as memórias obscuras, oclusas, que não assumem papel de destaque no cenário social (POLLACK, 1989), possibilitando visionar os sujeitos ocultos da sociedade e colocá-los, junto a sua memória, em evidência de estudo. Faz-se importante perceber que são esses "tipos" de sujeito e essa forma de memória que constituem o universo do carnaval, merecendo por isso tal abordagem analítica.

Cabe ao pesquisador, então, trazer para a academia o discurso da história oral, que existe muito antes de ter esse nome, e analisá-lo a seu favor, valorizando suas pluralidades e especificidades. Segundo Janaína Amado e Marieta de Moraes Ferreira (1996),

O fato de a história oral ser largamente praticada fora do mundo acadêmico, entre grupos e comunidades interessados em recuperar e construir sua própria memória tem gerado tensões (...) essa pluralidade (uma das marcas da história oral em todo o mundo), quando aceita, pode gerar um rico diálogo, raramente presente em outras áreas da história. 


\section{PASSADO E PRESENTE: O CASO DANIELLE NASCIMENTO}

A relação do passado com o presente apresenta-se de forma íntima, pois, para se entender o presente, por vezes é necessário ir buscar no passado justificativas que expliquem os acontecimentos contemporâneos (BLOCH, 2001). Esse diálogo assume caráter primordial no universo das escolas de samba, pois a todo momento o passado é evocado para explicar, justificar ou, singelamente, recordar um fato.

Pela amplitude alcançada e repercussão causada na mídia carnavalesca, além da representatividade que as escolas envolvidas possuem no cenário do carnaval carioca, vejamos o caso de Danielle Nascimento. Porta-bandeira pertencente à nova geração do carnaval carioca e filha de Wilma Nascimento, ${ }^{1}$ ao trocar a Im-

pério Serrano pela Portela provocou um dos grandes debates do Carnaval de 2009.

O passado de Wilma na Portela foi o fio condutor da negociação de Danielle, gerando expectativas múltiplas no tocante ao futuro da dançarina. A todo momento esse passado era trazido à tona para justificar por que o cargo era pertinente à Danielle. ${ }^{2}$

Luis Carlos Magalhães, responsável pela coluna “Memória da Folia", assim retratou o caso de Danielle:

E a cada palmo de pista, dance...dance...dance muito; com certeza sua mãe estará ali por dentro de você. E diga, junto com ela, que a história da sua família, a história da sua escola, é um pouco da história de cada um de nós, povo do samba, toda nossa gente, de todas as cores, de todos os "acessos" (fragmento da crônica "Carta à Daniele Nascimento", disponível no site www.odianafolia.com.br, acesso em 10.8.2010).

A crônica foi escrita após a assinatura do contrato da porta-bandeira com a Portela, o que foi motivo de grande comemoração e atenção não só pelos torcedores da escola, mas também pela maioria dos segmentos envolvidos no carnaval, incluindo a imprensa especializada:

Em reunião na noite desta quinta-feira, na quadra da Portela, o presidente da escola Nilo Figueiredo anunciou oficialmente o nome do novo casal de mestresala e porta-bandeira: Danielle Nascimento e Fabrício Pires. A contratação dos dois era um sonho do portelense. Danielle é filha de Wilma Nascimento, que por muitos anos reinou como porta-bandeira e é considerada o Cisne da Passarela (site www.carnavalesco.com.br, acesso em 17.7.2010).

Até mesmo após a contratação, gerou-se grande expectativa quanto ao desfile. Em matéria publicada um dia após o desfile da Portela, o jornal O Estado de São Paulo on line noticiou: "Destaque para o casal de mestre-sala e porta-bandeira, Fabrício e Danielle Nascimento. Ela, filha de Vilma Nascimento, que foi uma porta-bandeira que fez história na escola, conhecida como "cisne da passarela" (acesso em 14.6.2010). 
Portanto, observa-se como no mundo do carnaval o passado alicerça o "hoje" em relações constantes de trocas, e a memória pode ser convocada para dar substância a um fato do presente. A recorrência dos sambistas ao passado é uma das formas que servem de justificativa para suas ações e seus pensamentos.

\section{A PROBLEMÁTICA DA VALORIZAÇÃO DO PASSADO}

Mediante essa relação entre passado e presente, com a consequente produção de memória, se observam poucas políticas de preservação do passado, posto que não há na maioria das escolas ação eficaz de armazenamento de suas documentações nem arquivos audiovisuais ou atas de reunião, por exemplo.

A manutenção desse tipo de documentos se faz necessária, tornando-se primordial no tocante à análise dos processos internos do carnaval, principalmente em pesquisas futuras em que nosso próprio tempo presente será analisado.

Essa falta de cuidado com a manutenção do passado gera sérios problemas para nós, pesquisadores, ${ }^{3}$ quando buscamos incessantemente novas fontes para entender e analisar os fatos já ocorridos e que ainda ocorrem, dentro do universo do samba.

Segundo Ivanísia Maria Ferreira Lima, compositora da Unidos de Vila Isabel:

3 Por esse motivo, muitos pesquisadores utilizam a história oral como alternativa para a ausência de fontes. Não recaindo numa metodologia "tapa-buraco", mas sim a utilizando como complemento de fontes escritas ou como forma principal de pesquisa.

4 Para saber mais sobre as classificações hierárquicas nas escolas de samba, ver LIMA, 2009 e BARBIERI, 2010.

Pelo que sei a escola não tem nada pra preservar a memória, não. Não tem biblioteca, não tem museu. Nunca vi nenhum trabalho forte de preservação, assim... do passado. Nada. Acho uma pena isso, porque acho que essa coisa vai se perdendo. Tanta gente importante na Vila que já morreu, e não ficou nada registrado. Paulo Brasão, Irani Olho Verde... A história dessas pessoas morreu junto, né? (depoimento coletado na Marquês de Sapucaí, em 30.1.2010).

Esse problema também foi valorizado pelo ritmista Bernardo Sampaio:

Muita coisa se perdeu sobre o passado das agremiações por pura falta de consciência da importância histórica daquelas ações que os sambistas do passado estavam realizando. Canários das Laranjeiras, Em Cima da Hora, muita história que já se perdeu. A maioria dos presidentes não está nem aí pro passado das suas escolas. Só querem saber é de patrocínio" (depoimento coletado na Marquês de Sapucaí, em 30.1.2010).

É importante enfatizar que o precário - inexistente, em alguns casos - trabalho de preservação dessa memória não é restrito a nenhum modelo hierárquico de classificação das escolas, ${ }^{4}$ ou seja, não é um problema de ordem econômica, segundo o qual as escolas do grupo de acesso têm mais dificuldade do que as agremiações do grupo especial para confeccionar seus carnavais e também em preservar suas memórias: torna-se um problema estrutural, enraizado nas bases das escolas de samba, seja qual for seu grupo, segundo os depoimentos coletados. 
Com essa problemática latente, criam-se alternativas de preservação da memória forjadas por sujeitos sociais que se podem localizar à margem dos altos escalões das escolas de samba. ${ }^{5}$ Nessa perspectiva, emerge o trabalho dos sujeitos que, movidos pela paixão a suas escolas e ao carnaval, usam-na como combustível de trabalho, criando estratégias que culminam em ações de valorização do passado.

Entra em cena a figura de uma organização que daria conta não só de preservar essa memória "apagada" das escolas de samba, mas também de resgatá-la e disseminá-la: os departamentos culturais.
5 Os departamentos culturais podem ser ligados ou não à Presidência da escola, sendo na maioria dos casos compostos por torcedores, reafirmando assim seu caráter pessoal de ligação com a agremiação acima da ligação com a Presidência ou Administração central.

\section{O CASO DO SALGUEIRO}

Para investigar melhor a dinâmica desses setores, colhemos o depoimento de Gustavo Melo, diretor do Departamento Cultural do Grêmio Recreativo Escola de Samba Acadêmicos do Salgueiro, coletado em 30.1.2010, na Marquês de Sapucaí. A escolha foi feita com base na importância que o departamento possui para a própria história dessa instância no universo do carnaval carioca, servindo como referência para outros departamentos que surgiram posteriormente.

No caso do Salgueiro, o grupo se iniciou em 1996 na gestão do presidente Paulo César Mangano, já como departamento cultural - na contramão de outros que surgiram posteriormente, como o caso do Salve a Mocidade e dos Gresilenses, que se constituíram primeiramente como grupos autônomos. Tendo como mentores Eduardo Pinto e André Jobim, seu acervo foi constituído inicialmente pela curiosidade pessoal dos componentes do grupo.

Segundo o diretor, antes de qualquer estrutura organizacional, as estratégias de preservação do passado surgem em cena tomando caráter pessoal. A curiosidade que move esses atores, fazendo com que percorram livrarias, sebos, antiquários em busca de material para montar um acervo pessoal, é movida pelos laços afetivos que os unem a suas agremiações, e não por iniciativa da direção da escola efetivamente, com apoio financeiro e estrutural, por exemplo.

A princípio, o departamento se formou dividido em unidades regionais, tendo cada localidade um componente representante: Gustavo Melo, de Fortaleza, Bruno Pompeu, de São Paulo, Rodrigo Paes, de Curitiba, e André Jobim, de Manaus, além de Eduardo Pinto, do Rio de Janeiro. Segundo Gustavo Melo, esse esquema funcionava como se os representantes fossem "embaixadores do Salgueiro" fora do Rio de Janeiro, com a função de estabelecer contato dessas distintas regiões com o carnaval do Salgueiro e, consequentemente, com o Rio de Janeiro.

Em 2000 ocorreu o episódio de ruptura da unidade em que se encontrava até então o Departamento: 
houve uma cisão, um "racha" da diretoria cultural. O Eduardo Pinto continuou na Vice-Presidência, e o André Jobim saiu. Os "meninos" saíram por causa da briga porque não houve mais razão de ser. Não tinha mais razão de ser a existência dos departamentos culturais fora do Rio. Eu já estava morando no Rio, cheguei aqui em fevereiro de 2000. E a partir daí o Eduardo foi tocando junto comigo. E nisso entra o Paulinho, que é o Paulo César Barros, que deu muito apoio.

Partindo de Le Goff, é importante observar as tensões políticas que permeiam as relações internas de uma organização, nesse caso, o Departamento Cultural do Salgueiro. Segundo o autor, a memória adquire característica de detenção de poder e de disputas políticas em alguns grupos, seu detentor possuindo a ordem "do esquecer e do lembrar". O manuseamento da memória em prol desses interesses assume caráter de demonstração de força, ascensão e queda de poderes em embates.

Ocorrido o "racha" do Departamento por desavenças internas, a memória, escopo de constituição do Departamento Cultural, torna-se objeto de disputas e poder. Divide-se o grupo dessas tensões em dois: de um lado, os representantes de André Jobim, marcados pela descentralização territorial em torno do Rio de Janeiro; de outro lado, Eduardo Pinto e Gustavo Melo, que já moravam no Rio de Janeiro na época da cisão. Com a divisão, toda a memória coletada até então permanece com Eduardo Pinto e Gustavo Melo, transformando-os assim em vitoriosos dessa disputa, pois a maior parte do acervo e o cargo de diretores culturais com eles permaneceram.

Em 1996, o Departamento Cultural cria o site da Acadêmicos do Salgueiro seguindo a tendência de "digitalização da memória" (LE GOFF, 1996). Todo o acervo coletado ate então foi digitalizado, por dificuldades de armazenamento e com o intento de divulgar mais o trabalho e a memória da escola.

A partir de 1998 o site assumiu função de "vitrine da escola para o mundo inteiro" segundo Gustavo Melo, sendo feitas entrevistas com componentes da escola em seguida disponibilizadas no site.

Outro episódio de disputa que envolve a memória e o Departamento Cultural do Salgueiro ocorreu em 2005, quando o ex-presidente Paulo César Mangano "hackeou" o site do Departamento Cultural.

No contexto de disputa pelo poder, ao apagar do site a memória da escola, Mangano atinge não só o Departamento Cultural - que era sua oposição na disputa presidencial -, mas toda a instituição e sua memória. Segundo Gustavo Melo,

Com o passar do tempo fomos digitalizando todo o nosso acervo, pois não tínhamos onde manter aquilo tudo. A solução que encontramos era utilizar a ferramenta da internet, que nos possibilitou a digitalização de grande parte do nosso acervo. Mas, na eleição de 2005, quando apoiávamos outra chapa que não foi a do Mangano, ele mandou hackear nosso site, e perdemos tudo que tínhamos construído até ali. Foi um golpe muito duro pra gente. 
Essa memória teve ser "reconstituída" pelos membros do departamento, e desde então o site tornou-se referência até mesmo para outros departamentos culturais em acervo digitalizado e memória no carnaval carioca.

Nesse ritmo, surgiram posteriormente muitos outros grupos, compostos por esses sujeitos apaixonados por suas escolas que atuam na preservação de sua memória: Portela Web, da Portela, Gresilenses, da Imperatriz Leopoldinense, Salve a Mocidade, da Mocidade Independente de Padre Miguel, o recente grupo da Viradouro, entre outros que ainda estão em fase de planejamento.

\section{A CULTURA DOS DEPARTAMENTOS E A FUNÇÃO DE MEDIAÇÃO}

Os departamentos culturais adquirem lógica própria, segundo a qual podem atuar em ações variadas, mas prioritária e majoritariamente têm como norte a atuação em políticas que auxiliem a manutenção do passado da escola. Mesmo seguindo a tendência de se concentrar em instituições ou pessoas (LE GOFF, 1996), a memória assume postura inerente ao cotidiano das escolas e se dispõe como estrutura organizacional dentro da agremiação na forma de departamentos.

Faz-se necessário então refletir brevemente sobre o que consiste essa cultura dos departamentos.

Mediante diversos conceitos apresentados no caminho das ciências sociais referente à cultura, fica evidente a inexistência de um conceito uníssono no campo da antropologia sobre o assunto. Passeando por definições desde Tylor até Geertz, vê-se que cada qual possui especificidades, enfoques e prioridades. Não devemos, portanto, nos ater a conceitos "fechados", mas construir as ideias a partir das observações de campo. É necessário construir esse conceito constantemente, ressignificá-lo e transformá-lo sempre que possível.

Dessa forma, os departamentos culturais assumem lógica bicultural (BURKE, 1995), ou seja, travam contato simultaneamente com a cultura erudita e popular. Ainda, essa cultura nos departamentos possui movimento circular (GINZBURG, 1987) e transita entre as duas camadas forjando trocas e embasando a cultura como espaço hibrido.

O departamento, então, assume postura bivalente, ocorrendo essa interação desde o contato com o popular - em casos, por exemplo, de coleta de depoimentos de baianas, compositores, entre outros componentes - até o contato com as elites - em situações de promoções de seminários, simpósios, exposições.

Abordamos o conceito de mediação cultural utilizado por Volvele (1978), trazido ao mundo do samba por Maria Laura Cavalcanti (1999):

Michel Volvele utiliza a expressão 'mediador cultural' para qualificar o personagem que, na dialética entre cultura de elite e cultura popular, transita entre mundos diversos, ocupando inevitavelmente uma posição ambígua, podendo ser visto tanto no papel de cão de guarda das ideologias dominantes, como porta-voz das revoltas populares. 
6 Para saber mais sobre o tema comunidade, ver PAVÃO, 2005 e 2009.

7 Contribuem nesse sentido de preservação da memória a Liesa, como espaço de fomento e documentação do carnaval carioca e o Centro de Referência do Carnaval/ Uerj, como espaço de discussão e articulação da pesquisa sobre o carnaval em suas diversas manifestações no Brasil e no mundo.

A autora então propõe a visão do carnavalesco no exercício desse papel de mediador cultural. Porém, com o aumento de departamentos culturais no Rio de Janeiro, essas organizações também passam a exercer parte da função mediadora. Explica-se.

Ao organizar seminários para a escola apresentando suas memórias e figuras que a representam em personificação, levando-as a suas comunidades ${ }^{6}$ - como no caso da Mocidade e do Salgueiro - e ao participar da elaboração do enredo e sinopses junto à figura do carnavalesco - atualmente Renato Lage, no caso do Salgueiro -, os departamentos culturais também passam, pouco a pouco, a conquistar seu espaço no cenário intelectual do carnaval, sem deixar de lado seu contato com o popular, exercendo assim esse papel de intercessor e fomentador do papel dialético exercido em meio a esses grupos.

Assim, os departamentos surgem como figura complementar à do carnavalesco nessa dinâmica de mediação das culturas elitista e popular.

\section{CONCLUSÃO}

Segundo Michel Polack (1989), a memória pode servir como fator de pertencimento ou exclusão de um indivíduo em relação a algum grupo. No caso do universo do samba, a memória serve como elemento agregador e articulador entre o indivíduo e o contexto em que ele se insere.

Além disso, colabora para a construção de uma identidade - ou identidades, como preferem os pós-modernistas - individual ou coletiva, servindo como fundamento da construção desse conceito em um indivíduo ou grupo. Dessa forma, a memória colabora para a constituição dessas identidades no carnaval, forjando o caráter pessoal que essa manifestação adquire com os sujeitos.

A memória dentro das escolas de samba, então, flui de maneira particular, fazendo parte do cotidiano do sambista, mesmo que às vezes ele não perceba. Porém, é preciso que não se deixe essa memória ser silenciada, pois, à medida que ela desaparece, o próprio carnaval, que é constituído de muitas memórias, diminui sua cadência de recordação e consequentemente tem fadada sua existência. ${ }^{7}$

\section{REFERÊNCIAS BIBLIOGRÁFICAS}

AMADO, Janaína, FERREIRA, Marieta de Moraes. Usos e abusos da história oral. Rio de Janeiro: Fundação Getúlio Vargas, 1996.

BARBIERI, Ricardo José de Oliveira. Sociabilidade e conflito em pequena escola de samba: o Acadêmicos do Dendê da Ilha do Governador. Dissertação de Mestrado, UFRJ, 2010.

BLOCH, Marc. Apologia da história ou o ofício de historiador. Rio de Janeiro: Jorge Zahar, 2001. 
BURKE, Peter. Cultura popular na Europa Moderna. São Paulo: Companhia das Letras, 1995.

CAVALCANTI, Maria Laura Viveiros de Castro. O rito e o tempo: ensaios sobre o carnaval. Rio de Janeiro: Civilização Brasileira, 1999.

GINZBURG, Carlo. O queijo e os vermes - o cotidiano e as ideias de um moleiro perseguido pela Inquisição. São Paulo: Companhia das Letras, 1987.

LIMA, Nelson. Majestades da folia: a influência do "imaginário monárquico" nas manifestações do Rio de Janeiro. Textos escolhidos de cultura e arte populares, Rio de Janeiro, v.6, n.1, p. 107-114, 2009.

LE GOFF, J. História e memória. 2. ed. Campinas: Editora da Unicamp, 1996.

PAVÃO, Fábio. Uma comunidade em transformação: modernidade, organização e conflito nas escolas de samba. Dissertação (Mestrado em Antropologia) PPGA/UFF, Niterói, 2005.

. As escolas de samba e suas comunidades. Textos escolhidos de cultura e arte populares, Rio de Janeiro, v.6, n.1, p. 183-196, 2009.

POLLAK, Michael. Memória, esquecimento, silêncio. In Estudos Históricos, Rio de Janeiro, v. 2, n. 3, p. 3-15, 1989.

VOLVELE, Michel. Ideologias e mentalidades. São Paulo: Brasiliense, 1978.

Vinicius Ferreira Natal é graduado em história pela Universidade Federal Fluminense.

Artigo recebido em agosto de 2010 e aceito para publicação em outubro 2010. 
